\title{
İstilacı Tür Kestane Gal Arısı (Dryocosmus kuriphilus) Yasumatsu (Hymenoptera: Cynipidae)'nin Yeni Yayılış Alanları
}

\author{
Yafes YILDIZ ${ }^{*}$, İbrahim YILDIRIM $^{2}$, Ertan ALBAS $^{3}$, Cengiz BOSTANCI ${ }^{2}$, Onur \\ AYDOĞAN $^{2}$ \\ ${ }^{1 *}$ Bartın Üniversitesi, Orman Fakültesi, Orman Endüstri Mühendisliği Bölümü,74100, BARTIN \\ ${ }^{2}$ Bartın Tarım ve Orman İl Müdürlüğü, Bitkisel Üretim ve Bitki Sağlığı Şube Müdürlüğ̈̈, 74100, BARTIN \\ 3Zonguldak Tarım ve Orman İl Müdürlüğü, Bitkisel Üretim ve Bitki Sağlığı Şube Müdürlüğü, 67100, \\ ZONGULDAK
}

\section{Öz}

Ülkemizde ilk kez 2014 y1lında Yalova'da tespit edilen Dryocosmus kuriphilus Yasumatsu (Hymenoptera: Cynipidae) geçen süre zarfında kestane alanlarında yayılmaya devam etmiştir. Kestanenin en önemli zararlısı konumuna gelen Gal arısı ile mücadele çalışmaları devam etmekle birlikte zamanla diğer illerimizden de zararlının görüldügüüne dair tespitler bulunmaktadır. En son olarak ise Zonguldak ve Bartın illerinde yapılan arazi surveylerinde zararlının galleri tespit edilmiştir. Bu illerimizde şu an için sınırlı yayılışı bilinen zararlı ile bir an önce mücadele çalışmalarına başlanmalıdır.

Anahtar Kelimeler: Dryocosmus kuriphilus, Gal arısı, Zarar, Yayılış, Bartın, Zonguldak.

\section{New Spread Areas of Invasive Species Chestnut Gall Wasp Dryocosmus kuriphilus Yasumatsu (Hymenoptera: Cynipidae)}

\begin{abstract}
Dryocosmus kuriphilus Yasumatsu (Hymenoptera: Cynipidae), which was detected in Yalova for the first time in our country in 2014, continued to spread in the chestnut areas during the time passed. Although the efforts to control the chesnut gal wasp, which has become the most important pest of chestnut, continue, there are also findings that the pest has been seen in our other provinces over time. Finally, the galls of the pest were detected in the surveys conducted in Zonguldak and Bartın provinces. Management studies should be started as soon as possible with the pest in its limited distribution in these provinces.
\end{abstract}

Keywords: Dryocosmus kuriphilus, Chestnut gall wasp, Damage, Distribution, Bartın, Zonguldak. 


\section{Giriş}

İnsanlar ve ekosistemler için potansiyel zararlı olabilecek, zararlı organizmaların kendi doğal bölgeleri dışında başka bölgelere taşınması küresel çapta panik ve endişelere yol açmakta (Kenis vd. 2009; Kenis ve Branco 2010; Williams vd. 2010; Aukema vd. 2011) ve biyolojik çeşitlilik için büyük tehdit oluşturmaktadır (Oskay vd 2014).

Egzotik türler birçok insan aktivitesi ile yaşam alanlarından, doğal potansiyel dağılımları dışındaki yeni ekosistemlere yerleşmektedirler Özellikle küresel ticaretin gelişmesi ile birlikte bitkilerin artan uluslararası ticareti, bitki hastalık ve zararlılarının küresel çapta yayılmasında itici gücü oluşturmaktadır (Gehring, 2019). Artan Uluslararası bitki ticareti ve iklim değişikliği egzotik türlerin yabancı ekosistemlere yerleşmesinde coğrafi engellerin aşılmasına yardımcı olmaktadır (Oskay vd., 2014) İstilacı türler sadece biyolojik çeşitlilik için tehdit oluşturmakla kalmayıp, aynı zamanda ormancılık, tarım ve insan sağlığı için riskler oluşturmakta, bitki sağlığı çalışmalarında yüksek maliyetlere neden olmaktadırlar.

$\mathrm{Bu}$ bağlamda uluslar ve bölgeler arası ticaretin gelişmesine paralel olarak son on yıllık dönem içerisinde, Tuta absoluta, Metcalfa pruinosa, TSWV (Tomato Spotted Wilt Virus), Anoplophora chinensis, Garella musculana, Cydalima perspectalis, Orosanga japonica ve son olarak da Dryocosmus kuriphilus gibi, Zonguldak ve Bartın illeri faunasında bulunmayan türler bu illerde görülmeye başlanmıştır.

Dryocosmus kuriphilus, Castanea pumila ve C. alnifolia dışındaki tüm kestane türlerinde zarar yapmakta (CABI 2020) ve geniş yayılış alanı bulduğu ülkelerde kestanenin en önemli zararlısı olmuştur. Partenogenetik üreme kapasitesi ve gal oluşumunun sürgün, çiçek ve meyve üzerindeki zararı nedeniyle D. kuriphilus, kestane cinsinin en tehlikeli zararlılarından biri olarak kabul edilmektedir (Payne vd., 1983; Moriya vd., 1990; Aebi vd., 2006). Ülkemizin yerli bir türü olan Castanea sativa Mill. Karadeniz kıyısı boyunca geniş bir alanda yayılış yapmaktadır

Ülkemizde amenajman planı verilerine göre kestane ormanları yaklaşık 262.000 ha alanda yayılış göstermektedir. Zonguldak ve Bartın illerini kapsayan Zonguldak Orman Bölge Müdürlüğünde 27.151 ha kestane ormanı bulunmaktadır. Orman Genel Müdürlüğü tarafından hazırlanan 2013-2017 yıllarını kapsayan Kestane Eylem Planı'na göre 60 bin ton kestane üretimi ile Türkiye dünyada üçüncü sırada yer almaktadır (Anonim, 2012). TUIKK verilerine göre 2019 yllı için ülkemizin kestane üretimi 72.655 ton olup, Bartın ilimiz 5.933 ton ile 3. sirada, Zonguldak ilimiz ise 1.307 ton ile 10. sırada yer almışırı (TUIK, 2019)

Sağladığı fonksiyonlar itibari ile kestane ormanlarımız, ülkemizin en temel orman kaynaklarındandır. Kestane ormanlarımız, sağladığı odun hammaddesinin yanında, odun dışı ürün niteliğindeki meyvesi ve başta Batı Karadeniz bölgesi olmak üzere bal üretimine sağladığı katkı nedeniyle önemli ekonomik kaynaklarımızdır. Diğer bitki türleri gibi kestane de uzun yıllardan beri tüm dünyada olduğu gibi ülkemizde de biyotik ve abiyotik birçok zararlılar sebebiyle verim azalması ve yok olma tehdidiyle karşı karşıyadır. Daha önceleri yoğun olarak kestane dal kanseri ve mürekkep hastalığı ile mücadele edilirken son zamanlarda ülkemizde varlığı ilk kez 2014 yılında tespit edilen Kestane Gal Arısı, Dryocosmus kuriphilus Yasumatsu (Hymenoptera: Cynipidae) ana zararlı olmaya başlamış ve bu zararlı ile mücadele edilmeye çalışılmaktadır (Çetin vd., 2014).

Bu zararlı 2014 yılının Nisan ayında ilk kez Yalova'da tespit edilmiştir (Çetin vd., 2014). Kestane ağacının en önemli zararlısı konumuna gelen, Dryocosmus kuriphilus Yasumatsu (Hymenoptera: Cynipidae) Çin orjinli olup, dünya genelinde kestane ağaçlarında büyük zararlara neden olmaktadır. Aynı zamanda, $D$. kuriphilus EPPO (Avrupa ve Akdeniz Bitki Koruma Organizasyonu) tarafindan 2003 yllında A2 listesinde karantina etmeni olarak kabul edilmiştir (EPPO, 2005). Türkiye'de de 03.12.2011 tarihli Bitki Karantinası Yönetmeliğinde karantina etmeni olarak tanımlanmış ve varlığı bilinmeyen karantinaya tabi zararlı organizmalar içerisinde yer almıştır. 2016 yılında ise Ek 1-B listesine alınmıştır.

Zararlı, kestane tomurcuklarına yumurtalarını bırakarak oluşturduğu galler ile sürgün gelişimi ve çiçeklenmeyi engellemekte ve meyvede \% 50-70 arası verim kayıplarına neden olmakta, yoğun popülasyonları ağaç ölümlerine yol açmaktadır. Zararlı ilk kez 1929 yılında Çin'de tespit edilmiş ve Biorhiza sp. olarak isimlendirilmiş, Dryocosmus kuriphilus olarak ise ilk kez 1951 yılında K.Yasumatsu tarafından isimlendirilmiştir (Yasumatsu 1951; Murakami 1980). Zararlı doğal yayılış bölgesi olan Çin'in dışında ilk kez 1941 yılında Japonya'da tespit 
edilmiş, 1950 yıllarında ülkedeki tüm kestane alanlarına yayılmış ve meyve üretiminde önemli kayıplara sebep olmuştur (Shiraga, 1951; Oho \& Shimura, 1970; Murakami vd., 1980; Moriya vd., 2002). İlerleyen y1llarda ise yayılmaya devam etmiş 1958 yılında Kore (Cho \& Lee, 1963), Asya kıtası dışında da ilk kez 1974 yılında ABDGeorgia (Payne vd., 1975), daha sonra ikinci kayıt ise 2012 yılında Kanada'dan bildirilmiştir (Huber\&Read 2012). 1999'da Nepal'de (Ueno, 2006) tespit edilmiştir. Avrupa'da ise ilk kez 2002 yılında İtalya'da türün varlığ 1 bildirilmiştir (Brussino vd., 2002).

D. kuriphilus Avrupa kıtasında Slovenya (2004; Knapič vd. 2010), Fransa (2005; Aebi vd. 2006), İsviçre (Forster vd. 2009) Hollanda (2008; Eppo 2010), Macaristan (2009 yılında ilk tespit yapılmış eradike edildikten sonra tekrar 2013 yılında varlığı tespit edilmiş (EPPO, 2013a), Hırvatistan (2010; Matosevic vd. 2010), Slovakya (2011, Pástor vd. 2017), Çek Cumhuriyeti (2011; EPPO 2012), Almanya (2012; EPPO), İspanya (2012; Pujade-Villar ve Torrell 2013), Avusturya (2013; EPPO 2013c), Romanya (2013; Radócz vd. 2016), Portekiz (2014; EPPO 2014), Türkiye (2014; Çetin vd. 2014), Yunanistan (2014; Michaelakis vd. 2016), Bosna Hersek (2015; Delalic 2016), İngiltere (2015; Malumphy 2015), Belçika (2015; EPPO 2016) ve Rusya'nın Kuzey Kafkasya’ya (Gninenko ve Lyanguzov 2017) yayılmıştır (Şekil 1).

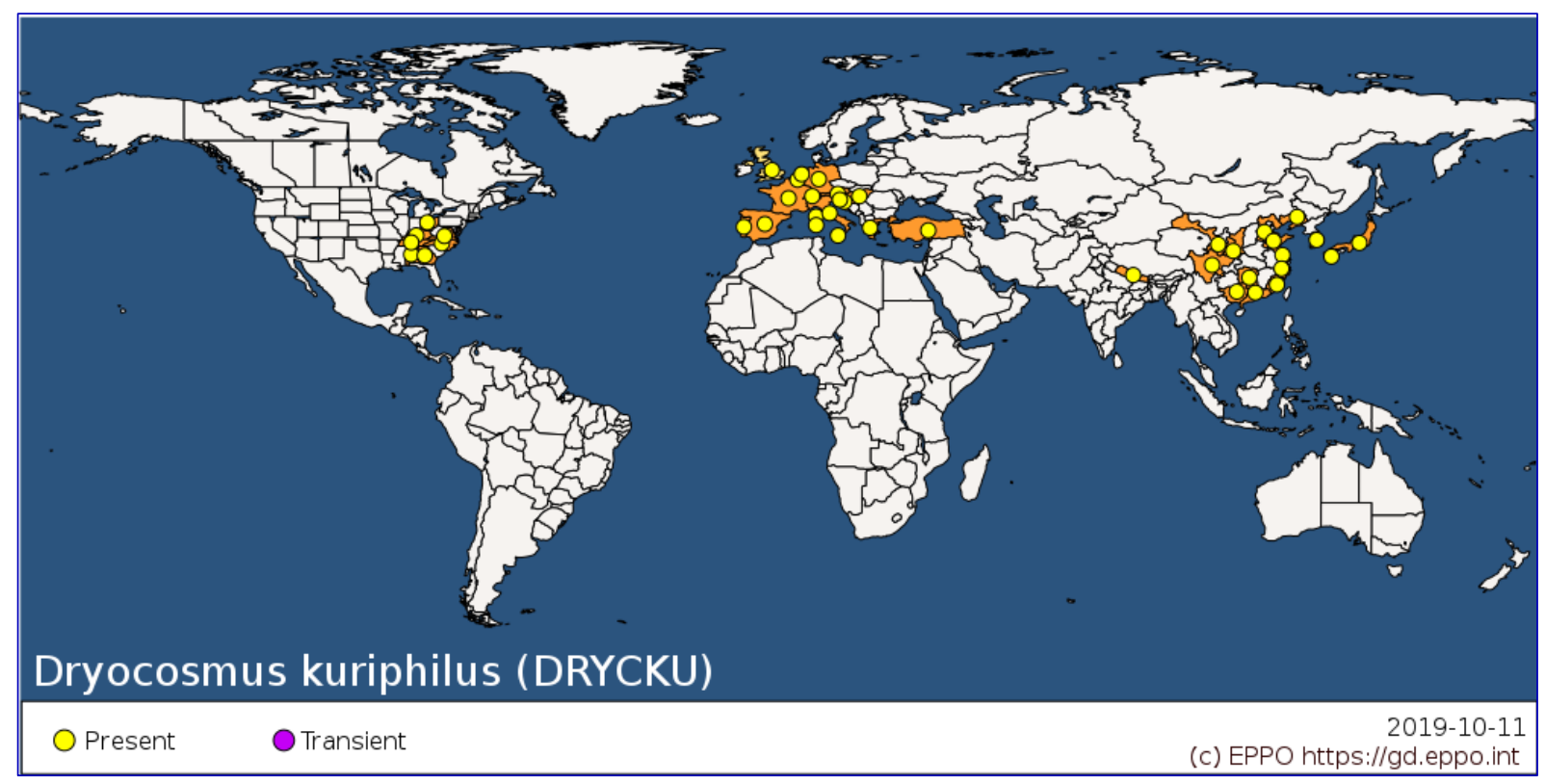

Şekil 1. Dryocosmus kuriphilus’un Dünyadaki güncel yayılışı (EPPO, 2020).

D.kuriphilus özellikle kestane ağaçlarına zarar vererek baharda yeni sürgünlerde gal oluşmasına neden olmaktadır. $\mathrm{Bu}$ nedenle sürgünlerin büyümesi engellenir ve bitkide oluşan gelişme geriliği nedeniyle önemli ölçüde verim kayıplarına neden olmaktadır (Kato ve Hijii, 1997). Yine D. kuriphilus zararına uğrayan kestane ağaçları farklı abiyotik ve biyotik faktörlere özellikle de Cryphonectria parasitica'ya karşı hassas olmaktadırlar (Prospero ve Forster 2011).

D.kuriphilus kestane çiçeklerine verdiği zarar nedeniyle özellikle Zonguldak ve Bartın illeri için önemli bir gelir getirici faaliyet olan kestane balı üretimi için yüksek risk oluşturmaktadır. İsviçre'de yapılan bir çalışmada $D$. kuriphilus zararı nedeniyle balların kompozisyonunda kestane bileşeninde \%30 kayıp meydana geldiği, kestane ağaçlarında zararın \%40’` aşması durumunda neredeyse kestane balının üretiminin mümkün olmadığı ortaya koyulmuştur (Gehring vd., 2018).

İlk tespitinden bu yana kestane ormanlarında yayılmaya devam eden zararlının Bartın ve Zonguldak illerindeki tespitinden sonra ülkemizde 11 ilde (Yalova, Bursa, İstanbul, Sakarya, Kocaeli, Balıkesir, Bilecik, Düzce, Giresun, Bartın, Zonguldak) yayılış yaptı̆̆ı bilinmektedir (Şekil 2). 


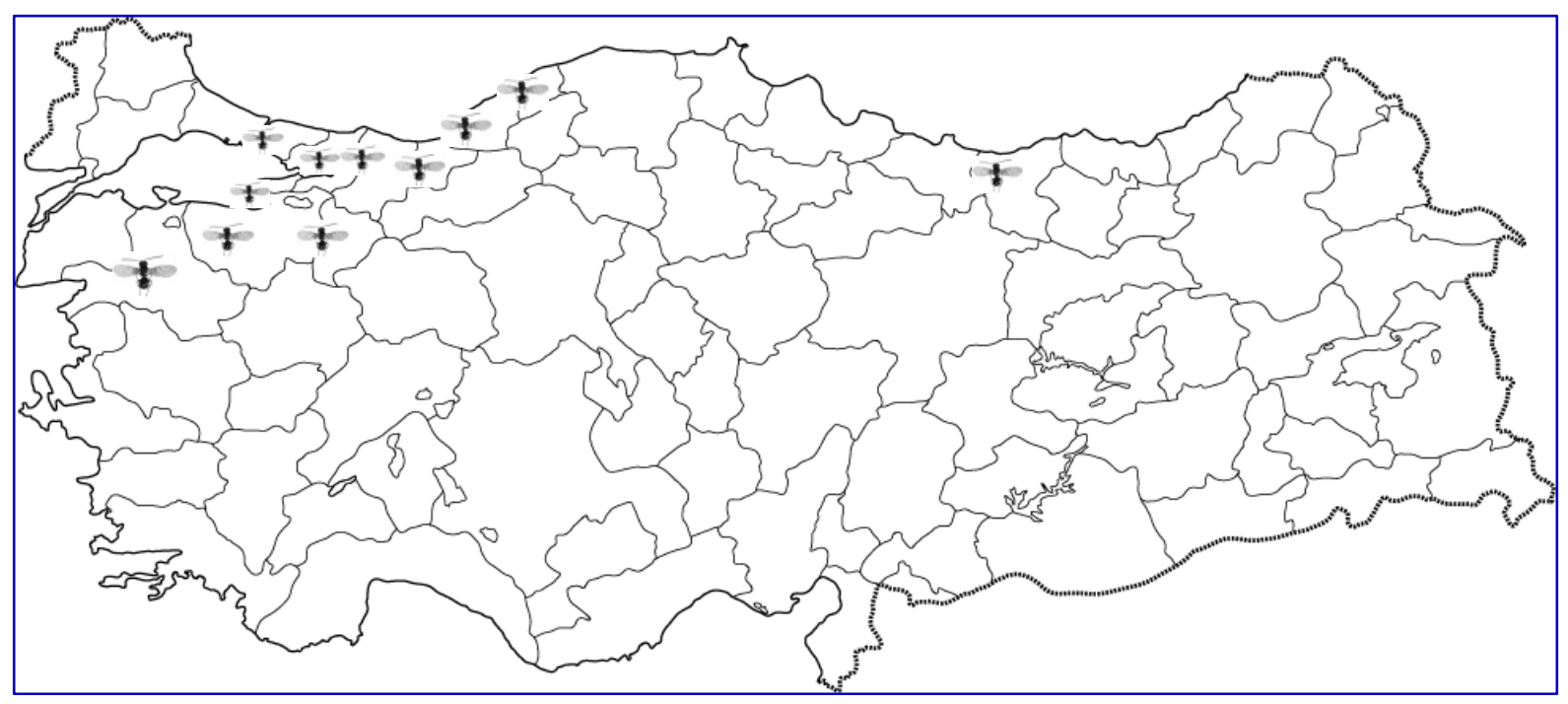

Şekil 2. Dryocosmus kuriphilus'un Türkiye'deki güncel yayılışı.

\section{Materyal ve Metot}

Çalışmanın materyalini Bartın ve Zonguldak kestane ormanları ve bu ormanlardaki kestane ağaçlarından toplanan dal ve yapraklarındaki gal örnekleri oluşturmaktadır. Bu amaçla arazide gallerin tespit edildiği ağaçların koordinatları el GPS i yardımı ile alınmış, fotoğrafları çekilmiş ve bulaşık materyaller incelenmek üzere laboratuar ortamına getirilmiştir. Yine laboratuar ortamında bazı galler kesilerek larva fotoğraflanmış ve bazı galler ise takip edilmek üzere kültüre alınmıştır.

\section{Bulgular}

Yapılan survey çalışmaları neticesinde Bartın ve Zonguldak illerindeki bulunan kestane ormanlarında D. kuriphilus galleri tespit edilmiştir (Şekil 3, Tablo 1). Zararlının sadece deniz kıyısındaki kestane ağaçlarında kalmayıp iç kesimlerdeki daha yüksek alanlara da geçtiği görülmüştür. Tespit edilen ağaçların dallarındaki gallerin çoğunluğunun yeşil formasyonda oldukları görülmüştür. Zamanla bu gallerin kırmızımtırak renklere döndükleri görülmüştür. Bazı lokasyonlarda kuruyan (geçen seneki) gallere de rastlanılmıştır. Bu durum gal arısının geçen sene de bu bölgede bulunduğunun kanıtıdır. Laboratuar ortamına getirilerek temizlenen gallerden haziran başında ergin çıkışları olmuştur. Zonguldak ilinde tek ağaç düzeyinde yapılan gözlemlerde dallardaki gal sayılarının Bartın iline göre yüksek olduğu görülmüştür. Açılan gallerde Bartın ilinde en fazla 6 adet larva ve pupa tespit edilirken, Zonguldak ilinde bu sayı 11 olarak tespit edilmiştir (Şekil 4).

Tablo 1. Dryocosmus kuriphilus in Bartın ve Zonguldak illerinde tespit edildiği lokaliteler.

\begin{tabular}{|c|c|c|c|}
\hline Tarih & Lokalite & Konum & Yükselti (m) \\
\hline 20.05 .2020 & Zonguldak-Göbü & $\begin{array}{l}41,3124 \mathrm{~K} \\
31,5821 \mathrm{D}\end{array}$ & 50 \\
\hline 03.06.2020 & Zonguldak - Kırımsa & $\begin{array}{l}41,2901 \mathrm{~K} \\
31,5332 \mathrm{D}\end{array}$ & 183 \\
\hline 03.06.2020 & Zonguldak - Muslu & $\begin{array}{l}41,3108 \mathrm{~K} \\
31,5631 \mathrm{D}\end{array}$ & 41 \\
\hline 03.06.2020 & Zonguldak - Saltukova & $\begin{array}{l}41,3216 \mathrm{~K} \\
32,0429 \mathrm{D}\end{array}$ & 19 \\
\hline 03.06.2020 & Zonguldak-Göbü-Şirinköy & $\begin{array}{l}41,3011 \mathrm{~K} \\
31,5747 \mathrm{D}\end{array}$ & 253 \\
\hline 03.06.2020 & Zonguldak - Gelik & $\begin{array}{l}41,2832 \mathrm{~K} \\
31,5237 \mathrm{D}\end{array}$ & 119 \\
\hline
\end{tabular}


Tablo 1. Devam ediyor.

\begin{tabular}{|c|c|c|c|}
\hline Tarih & Lokalite & Konum & Yükselti (m) \\
\hline 03.06.2020 & Zonguldak-Dilaver & $\begin{array}{l}41,2632 \mathrm{~K} \\
31,5037 \mathrm{D}\end{array}$ & 268 \\
\hline 10.06.2020 & Çaycuma-Yazıköy & $\begin{array}{l}41,2403 \mathrm{~K} \\
32,1453 \mathrm{D}\end{array}$ & 223 \\
\hline 15.06.2020 & Çaycuma-Güzelyaka & $\begin{array}{l}41,2552 \mathrm{~K} \\
32,1453 \mathrm{D}\end{array}$ & 223 \\
\hline 20.05.2020 & Bartın-Büyük Kızılkum & $\begin{array}{l}41,3534 \mathrm{~K} \\
32,0652 \mathrm{D}\end{array}$ & 73 \\
\hline 20.05.2020 & Bartın - Büyük Kızılkum & $\begin{array}{l}41,3530 \mathrm{~K} \\
32,0709 \mathrm{D}\end{array}$ & 73 \\
\hline 01.06.2020 & Bartın-Arıönü & $\begin{array}{l}41,3635 \mathrm{~K} \\
32,0938 \mathrm{D}\end{array}$ & 27 \\
\hline 01.06.2020 & Bartın-Güzelcehısar & $\begin{array}{l}41,3720 \mathrm{~K} \\
32,1044 \mathrm{D}\end{array}$ & 262 \\
\hline 04.06.2020 & Bartın-Sofular & $\begin{array}{l}41,2912 \mathrm{~K} \\
32,2354 \mathrm{D}\end{array}$ & 245 \\
\hline 09.06.2020 & Bartın - Güzelcehisar & $\begin{array}{l}41,3826 \mathrm{~K} \\
32,1123 \mathrm{D}\end{array}$ & 140 \\
\hline 11.06.2020 & Bartın-Kirsinler & $\begin{array}{l}41,2857 \mathrm{~K} \\
32,2535 \mathrm{D}\end{array}$ & 609 \\
\hline 19.06.2020 & Bartın-Kızıllar & $\begin{array}{l}41,2327 \mathrm{~K} \\
32,3011 \mathrm{D}\end{array}$ & 596 \\
\hline
\end{tabular}

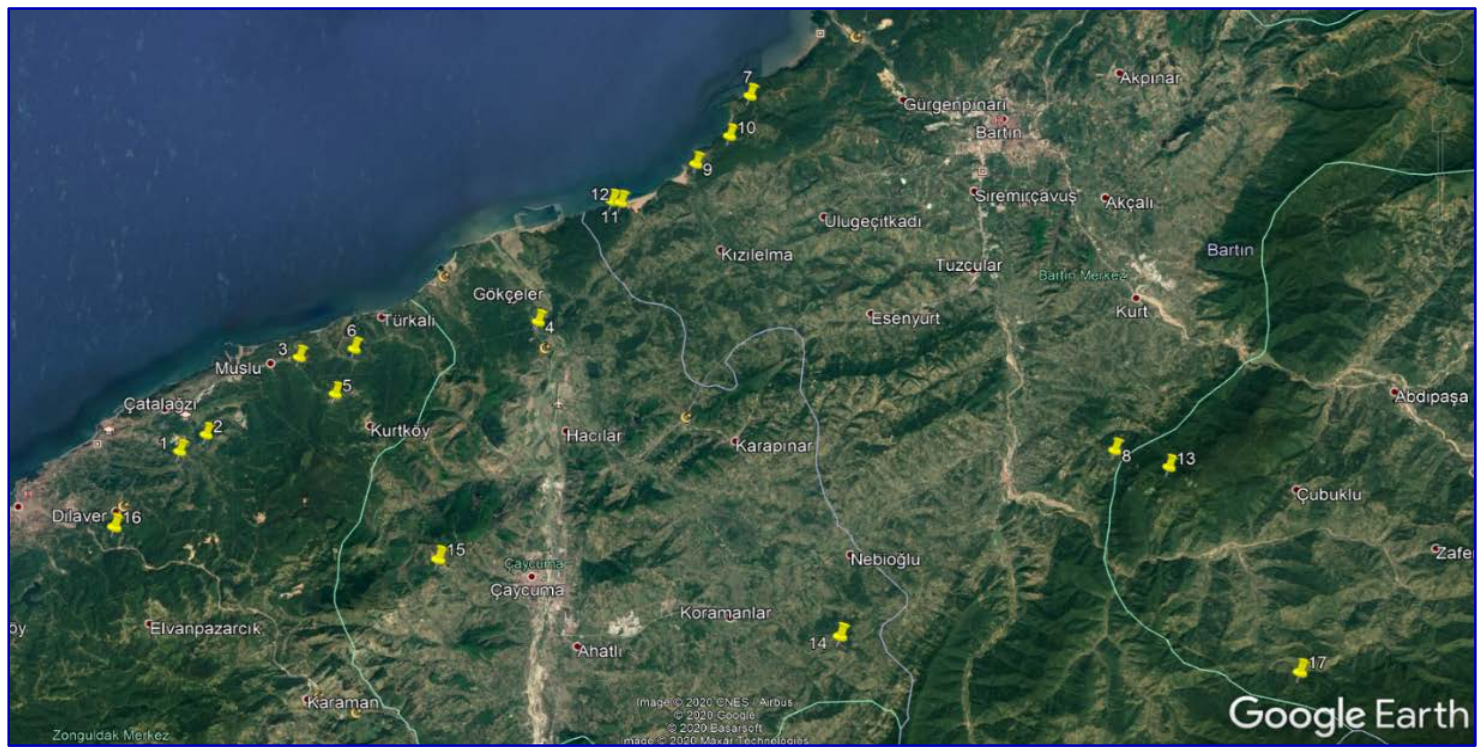

Şekil 3. Dryocosmus kuriphilus in Bartın ve Zonguldak illerinde tespit edildiği lokaliteler. 


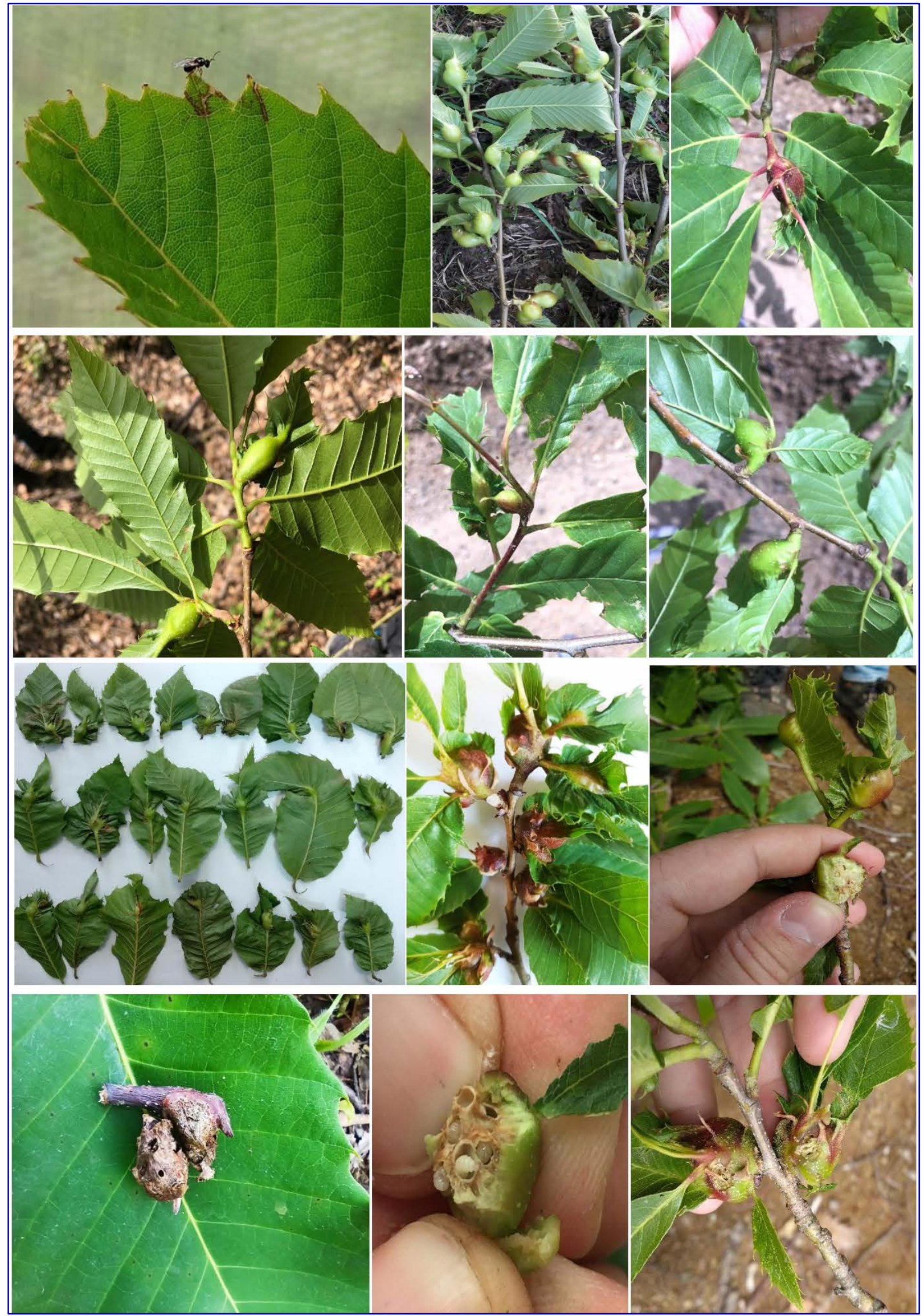

Şekil 4. D. kuriphilus ve zararı sonucu oluşan gal kompleksleri. 


\section{Sonuç ve Öneriler}

Yurdumuzdaki ilk tespitinden sonra yayılış alanın giderek genişleyeceği ve bulaşık alanların artacağı düşünülen zararlı son olarak Bartın ve Zonguldak illerinde de tespit edilmiştir. Yapılan surveylerde zararlının sınırlı bir yayılışı olduğu düşünülmekte, survey çalışmaları devam etmektedir. Fakat dünyada ve ülkemizde kısa sürede geniş alanlara yayılması ve mücadelesinin zor olması, türün yeni tespit edilen alanlardan başta komşu kestane ormanları olmak üzere kısa sürede diğer kestane alanlarına geçebileceğini göstermektedir.

Kestane gal arısı, Dünya'nın birçok yerine bulaşmış ve yayılış gösteren bir türdür. Bu denli yaygın olmasının sebepleri olarak partenogenetik (döllemsiz) üreme yeteneği (Nohara, 1956) ve yetiştiricileri arasında kestane üretim materyali alışverişi (Aebi vd., 2006) gösterilmektedir. Ayrıca rüzgar faktörü de zararlının yayılma uzaklığını ve hızını da etkileyebilmektedir. Nitekim yıllık yayılma hızının ortalama $25 \mathrm{~km}$ (Rieske, 2007 ve Graziosi \& Santi, 2008) olarak bildirilen zararlının, kişisel görüşme neticesinde İtalya'da rüzgar ve diğer taşınma yollarına da bağlı olarak 100 km/yıl gibi yüksek bir yayılma hızına ulaştığı tespit edilmiştir (İpekdal vd, 2014).

Ülkemizde yayılışı üzerine yapılan çalışmalarda kestane gal arısının 2014'ten 2018'e kadar yayılış alanını kuzey, güney ve doğu yönlerinde yaklaşı olarak $100 \mathrm{~km}$ kadar genişlettiği görülmüş bu da yılda yaklaşık $25 \mathrm{~km}$ gibi bir doğal yayılış hızını denk geldiği bildirilmiştir (Şah, 2019). Türün ekonomik anlamda bölgemiz açısından başta kestane meyvesi ve kestane balı üretimi olmak üzere büyük verim düşüşüne sebep olacağı bir gerçektir. Türün önemine binaen 17 Haziran 2014 tarihinde Kestane Gal Arısı ile diğer 3 zararının (Ani Meşe Ölümü, Çam Çıralı Kanser Hastalığı ve Turunçgil Uzun Antenli Böceği) mücadelesi hakkında yönetmelik dahi çıkarılmıştır (URL-2, 2020).

Ülkemizde kestanenin önemli üretim merkezlerinden olan İzmir ve Aydın illerinde şu an görülmeyen zararlının bu alanlara yayılması kestane üretimi açısından büyük bir risk oluşturmakta ve ciddi ekonomik kayıplara neden olacaktır.

Zararlının daha geniş alanlara yayılması önlemek, bulunduğu alanlarda ise kontrol altına alınabilmesi için bir an önce eradikasyon çalışmalarına başlanmalıdır. Mücadelesi şu an için sadece Torymus sinensis parazitoit türle yapılabilen zararlıya karşı parazitoitin bulunduğu bölgelerden bulaşık alanlara nakil ve salımın yapılması gerekmektedir. Fakat bu sürecin başarılı olmasının uzun yılları alacağı unutulmamalıdır. Bu çalışmalara ilaveten T. sinensis'in zararlı üzerindeki etkinliğinin belirlenebilmesi için daha kapsamlı çalışmalar yapılmalı, bu egzotik parazitoidin yerli parazitoit türlerle etkileşimi de araştırılmalıdır. Ayrıca iller ve bölgeler arası kestane üretim materyalinin dolaşımı kontrol altında tutulmalı ve karantina koşulları titizlikle uygulanmalıdır. Zararlının yayılışının ve zararının önlenebilmesi noktasında zararlıya karşı dayanıklı ırkların araştırılmasına devam edilmeli ve entegre mücadele noktasında ise biyolojik mücadeleye ek olarak daha başka mücadele yöntemlerinin bulunmasına çalışılmalıdır. Aslında tek başına hiçbir yöntem tüm bitki sağlığı sorunlarını uzun vadede çözmeye yeterli değildir. Bu nedenle en doğrusu Entegre Zararlı Yönetimi (IPM) olarak tarif edilen ve bütün tekniklerin bir arada ve optimum düzeyde sürdürülebilirliği öngörecek şekilde kullanıldığı bir yaklaşımla bitki sağlığı sorunlarının çözümüdür. Dayanıklı tohum seçimi ile başlayan bu yöntemde, uygun üretim tekniklerinin kullanımı hastalık, zararlı ve faydalı popülasyonunun sürekli takibi ve ihtiyaç duyulması halinde üretim alanındaki faydalılara en az zararlı olacak şekilde, kültürel, fiziksel, biyoteknik, biyolojik ve kimyasal mücadele yöntemlerinin kullanımı mümkündür (Anonim, 2018). Tosi ve ark., 2014, tarafından yapılan bir çalışmada; ekzotik parazitoitlerin kullanımına izin verilmeyen alanlarda, Fusarium profileratum' un $D$. kuriphilus' un kontrolü için ümit verici bir fungal biyo-kontrol ajanı olduğu tespit edilmiştir (Tosi ve ark., 2014).

\section{Kaynaklar}

1. Aebi A, K Schönrogge, G Melika, A Alma, G Bosio, A Quacchia, L Picciau, Y Abe, S Moriya, K Yara, G. Seljak \& GN Stone (2006). "Parasitoid Recruitment to the Globally Invasive Chestnut Gall Wasp Dryocosmus kuriphilus 103-121”. In: Galling Arthropods and Their Associates, Ecology and Evolution, (Ed: Ozaki, K., J. Yukawa, T. Ohgushi \& P.W. Price), Springer-Verlag, Tokyo, 240 pp.

2. Anonim (2012). Kestane Eylem Planı 2013-2017. Orman Genel Müdürlüğü. Ankara. 
3. Anonim (2018). Teoriden Pratiğe Biyoteknik Mücadele. Gıda ve Kontrol Genel Müdürlüğü. Ankara.

4. Aukema J, Leung B, Kovacs K, Chivers C, Britton K, Englin J, Frankel S, Haight R, Holmes T, Liebhold A, McCullough, D, Von Holle, B, (2011). Economic impacts of non-native forest insects in the continental United States. PLos ONE 6, e24587

5. Brussino G, G Bosio, M Baudino, R Giordano, F Ramello \& G Melika (2002). Pericoloso insetto esotico per il castagno europeo. Informatore Agrario, 58: 59-61.

6. CABI (2020). https://www.cabi.org/isc/datasheet/20005

7. Cho, DY \& SO Lee (1963). Ecological studies on the chestnut gall wasp, Dryocosmus kuriphilus Yasumatsu, and observation on the damages of the chestnut trees by its insect. Korean Journal of Plant Protection, 2: 4754.

8. Çetin, G., E. Orman \& Z. Polat (2014). First record of the oriental chestnut gall wasp, Dryocosmus kuriphilus Yasumatsu (Hymenoptera: Cynipidae) in Turkey. Bitki Koruma Bülteni, 54(4): 303-309.

9. Delalic Z (2016) First record of quarantine pest, oriental chestnut gall wasp (Dryocosmus kuriphilus), in Bosnia and Herzegovina. Biljn Lek (Plant Dr 44:58-65. doi: http://dx.doi.org/10.1136/adc.2006.104778

10. EPPO (2005) Data sheets on quarantine pests - Dryocosmus kuriphilus. EPPO Bulletin, 35: $422-424$.

11. EPPO (2010) First report of Dryocosmus kuriphilus in the Netherlands. EPPO Report Serv 8:134

12. EPPO (2012) First report of Dryocosmus kuriphilus in Czech Republic. EPPO Report Serv 141:1

13. EPPO (2013a) Dryocosmus kuriphilus found in Hungary. EPPO Report Serv 142:1-2

14. EPPO (2013b) First report of Dryocosmus kuriphilus in Germany. EPPO Report Serv 141:1

15. EPPO (2013c) First report of Dryocosmus kuriphilus in Austria. EPPO Report Serv 140

16. EPPO (2014) First report of Dryocosmus kuriphilus in Portugal. EPPO Report Serv 103:1

17. EPPO (2016) First report of Dryocosmus kuriphilus in Belgium. EPPO Report Serv 29:1

18. EPPO (2020) https://gd.eppo.int/taxon/DRYCKU/distribution

19. Forster B, Castellazzi T, Colombi L (2009) Die Edelkastaniengallwespe Dryocosmus kuriphilus (Yasumatsu) (Hymenoptera, Cynipidae) tritt erstmals in der Südschweiz auf. Mitteilungen der Schweizischen Entomol Gesellschaft 82:271-279

20. Gninenko YI, Lyanguzov ME (2017) East chestnut gall wasps Dryocosmus kuriphilus Yasumatsu, 1951 (Hymenoptera, Cynipidae)—New invader in the forests of the North Caucasus. Russ J Biol Invasions 8:206211. doi: 10.1134/S207511171703002X

21. Graziosi, I \& F Santi (2008). Chestnut gall wasp (Dryocosmus kuriphilus): spreading in Italy and new records in Bologna province. Bulletin of Insectology, 61 (2): 343-348.

22. Gehring E, Kast C, Kilchenmann V, Bieri K, Gehrig R, Pezzatti GB, Conedera M (2018). Impact of the Asian Chestnut Gall Wasp, Dryocosmus kuriphilus (Hymenoptera, Cynipidae), on the chestnut component of honey in the southern Swiss Alps. Published in Journal of Economic Entomology, 111: 43-52, https://doi.org/10.1093/jee/tox338

23. Gehring E (2019). Evolution of the Castanea sativa - Dryocosmus kuriphilus -Torymus sinensis - system in southern Switzerland Phd. Thesis The Faculty of Sciences of the University of Neuchâtel

24. Huber JT, Read J (2012). First record of the oriental chestnut gall wasp, Dryocosmus kuriphilus Yasumatsu (Hymenoptera: Cynipidae), in Canada. J Entomol Soc Ontario 143:125-128

25. İpekdal K, KS Coşkuncu, F Aytar \& M Doğanlar (2014). Kestane gal arısı Dryocosmus kuriphilus Yasumatsu (Hymenoptera: Cynipidae): Geçmisten günümüze dünyada ve Türkiye'deki son durumu ve mücadelesi. Türkiye Entomoloji Bülteni, 4(4): 241-257.

26. Kato K \& N Hijii (1997). Effects of gall formation by Dryocosmus kuriphilus Yasumatsu (Hym., Cynipidae) on the growth of chestnut trees. Japanese Journal of Applied Entomology, 121: 9-15.

27. Kenis, M, Auger-Rozenberg, MA, Roques A, Timms Péré, C Cock, MJW, Settele J Augustin, S LopezVaamonde C (2009). Ecological effects of invasive alien insects. Biol. İnv. 11, 21-45

28. Kennis M, Branco M (2010). İmpsct of alien terrestrial arthropods in Europe. BioRisk 4, 51-75.

29. Knapič V, Seljak G, Kolšek M (2010). Experience with Dryocosmus kuriphilus Yasumatsu eradication measures in Slovenia. OEPP/EPPO Bull 31 169-175

30. Malumphy C (2015). First findings of oriental chestnut gael wasp Dryocosmus kuriphilus Yasumatsu (Hymenoptera: Cynipidae) in the United Kingdom. Cecidology 30:45-47

31. Matosevic D, Pernek M, Hraśovec B (2010). First record of oriental chestnut gall wasp (Dryocosmus kuriphilus) in Croatia. Šumarski List 134:497-502

32. Michaelakis A, Papachristos D, Chytas DA (2016). First record of Dryocosmus kuriphilus in Greece. EPPO Bull 46:290 294. doi: 10.1111/ epp.12305 
33. Moriya S, K Inoue \& Mabuchi M (1989). The use of Torymus sinensis to control chestnut gall-wasp, Dryocosmus kuriphilus, in Japan. Technical Bulletin of the Food and Fertilizer Technology Center, 118: 112.

34. Moriya S, K Inoue and Mabuchi M (1990). The use of Torymus sinensis to control chestnut gall wasp, Dryocosmus kuriphilus, in Japan, pp.94-105. In Bay-Petersen, J. (ed.), Proceedings of an International Seminar on the Use of Natural Enemies to Control Agricultural Pests,

35. Moriya S, M Shiga \& I Adachi (2002). “Classical Biological Control of the Chestnut Gall Wasp in Japan”. Proceedings of the 1st International Symposium on Biological Control of Arthropods (14-18 January 2002, Honolulu, Hawaii), United States Department of Agriculture, Forest Service, Washington, DC, USA, 407415 pp.

36. Murakami Y (1980). Current topics on the chestnut gall wasp - experience in China. Nogyo oyobi Engei (Agriculture Hortic 55:249-253

37. Murakami Y, HB Ao \& CH Chang (1980). Natural enemies of the chestnut gall wasp in Hopei Province, China (Hymenoptera: Chalcidoidea). Applied Entomology and Zoology, 15: 184-186.

38. Nohara K (1956). Considerations on the reproductive capacity of Dryocosmus kuriphilus Yasumatsu (Hymenoptera: Cynipidae). Scientific Bulletin Faculty of Agriculture Kyushu University, 15: 441-446.

39. Oho N. \& Shimura I (1970). Process of study on Dryocosmus kuriphilus Yasumatsu (Hymenoptera: Cynipidae) and several problems about recent infestation. Plant Protection, 24: 421-427.

40. Oskay F, Lehtijarvi A, Doğmuş-Lehtijarvi HT, Aday Kaya, AG (2014). Forest Pathogens in a changing world; alien invasive species and threats to our forestry. Türkiye II. Orman Entomolojisi ve Patolojisi Sempozyumu, 475-486.

41. Pástor M, Juhásová G, Juhás D (2017). Occurrence of oriental chestnut gall wasp Dryocosmus kuriphilus in Slovakia - Short communication. Plant Prot Sci 53:243-246. doi: 10.17221/171/2016-PPS

42. Payne JA, AS Menke \& Schroeder PM (1975). Dryocosmus kuriphilus Yasumatsu (Hymenoptera: Cynipidae), an oriental chestnut gall wasp in North America. U.S. Department of Agriculture Cooperative Economic Insect Report, 25: 903-905.

43. Payne JA, RA Jaynes and Kays SJ (1983). Chinese chestnut production in the United States - Practice, problems, and possible solutions. Economic Botany 37: 187-200

44. Prospero S, Forster B (2011). Chestnut gall wasp (Dryocosmus kuriphilus) infestations: new opportunities for the chestnut blight fungus Cryphonectria parasitica? New Dis Reports 23:35. doi: 10.2307/3807741

45. Pujade-Villar J, Torrell A (2013). Primeres troballes a la península Ibèrica de Dryocosmus kuriphilus (Hym., Cynipidae), una espècie de cinípid de origen asiàtic altament perillosa per al castanyer (Fagaceae). Orsis 27:295-302

46. Radócz L, Szilágyi A, Nagy M (2016). Asian sweet chestnut gallwasp, Dryocosmus kuriphilus (Hymenoptera, Cynipidae): First record for Romania. North West J Zool.

47. Rieske LK (2007). Success of an exotic gallmaker, Dryocosmus kuriphilus, on chestnut in the USA: a historical account. EPPO Bulletin. 37: 172-174.

48. Shiraga T (1951). Chestnut gall wasps and the control. Journal of Agriculture and Horticulture, 26: 167-170.

49. Soylu A, Serdar Ü, Eratan E Mert, C (2009). Turkey. Following Chestnut Footprints (Castanea spp.) Cultivation and Culture. Folklore and History. Traditions and Uses. Published by ISHS.Scripata Horticulturae N. 9.

50.Şah S (2019). Türkiye'de Kestane Gal Arısının [Dryocosmus kuriphilus Yasumatsu (Hymenoptera: Cynipidae)] yayılışı ve zarar oranının belirlenmesi. Isparta Uygulamalı Bilimler Üniversitesi Lisansüstü Eğitim Enstitüsü, Yüksek lisans tezi, 52s., Isparta

51. Tosi L, Beccari G, Rondoni G, Covarelli G, Ricci C (2014). Natural occurrence of Fusarium proliferatum on chestnut in Italy and its potential entomopathogenicity against the Asian chestnut gall wasp Dryocosmus kuriphilus. Journal of Pest Sciences, DOI 10.1007/s10340-014-0624-0.

52. TÜİK (2019). http://www.tuik.gov.tr/PreHaberBultenleri.do?id=33740

53. Ueno W (2006). Occurrence and control of chestnut gall wasp in Nepal. Plant Protection, 60: 510-512.

54. URL-2 (2020). https://www.resmigazete.gov.tr/eskiler/2014/06/20140617-7.htm

55. Yasumatsu K (1951). A new Dryocosmus injurious to chestnut trees in Japan (Hymenoptera: Cynipidae). Mushi 22:89-92

56. Williams F, Eschen R, Harris A, Djeddour D, Pratt C, Shaw R, Varia S, Lamontagne-Godwin J, Thomas S, Murph S (2010). The cost of impact of invasive non-native species on Great Britain. CABI, Wallingford. 